\title{
Economic Evaluation of Three Available Solutions for Promotion of Wind Power Integration
}

\author{
Hong-Kun Chen, ${ }^{1}$ Yan-Juan Yu, ${ }^{1}$ Lei Chen, ${ }^{1}$ Xin Jiang, ${ }^{1}$ and Ren-Yan Yu ${ }^{2}$ \\ ${ }^{1}$ School of Electrical Engineering, Wuhan University, Wuhan 430072, China \\ ${ }^{2}$ North Electro-Optics Group Co., Ltd., Xian 710065, China \\ Correspondence should be addressed to Hong-Kun Chen; chkinsz@163.com
}

Received 9 February 2017; Accepted 23 March 2017; Published 5 April 2017

Academic Editor: Tariq Iqbal

Copyright (c) 2017 Hong-Kun Chen et al. This is an open access article distributed under the Creative Commons Attribution License, which permits unrestricted use, distribution, and reproduction in any medium, provided the original work is properly cited.

\begin{abstract}
The limited operational flexibility of combined heat and power (CHP) units is the main cause of wind power curtailment in the thermal-electrical power system of Northern China. Pumped hydrostorage (PHS), heat storage (HS), and electric boiler (EB) are investigated as three alternative options for the promotion of wind power integration. On the basis of two linear models that determine the capacities of these three facilities required for integrating the curtailed wind power, economic evaluation in terms of investment costs and environmental benefits is presented. Analysis results show that HS requires the least investment and has a good performance of coal saving when accommodating the same amount of curtailed wind power. And EB has the greatest potential for wind power integration with the huge growth of installed capacity of wind power in the future.
\end{abstract}

\section{Introduction}

With the rapid growth of wind power, it has been a mainstream green energy source in many countries, as well as in China [1]. But a large amount of wind power has to be wasted in the heating season due to the limited flexibility of the combined heat and power (CHP) units, especially in Northern China where the CHP units account for a large share of the generators [2]. CHP units cannot supply adequate downward regulating space for wind power since the production of electricity is strongly dependent on heat demand in the cogeneration system [3]. In view of this situation, wasted wind power is supposed to be reduced by either accumulating directly with electrical storage devices or decoupling heat and power demand with heat compensation devices.

Potential options for electrical storage include electrochemical energy storage, electromagnetic energy storage, and mechanical energy storage $[4,5]$. However, most of the electrical storages need vast investment and have not been in the commercial application except pumped hydrostorage (PHS) [6]. PHS is well known as the most promising energy storage technology, accounting for $99 \%$ of the available electrical storage capacity all over the world. And it has a good performance of frequency control and peak load shifting [7]. Comprehensive benefits of introducing PHS for the promotion of wind power accommodation have been analyzed in [8-11], which achieve an agreement that PHS could get costeffective peak-shaving as well as the reduction in carbon dioxide emissions. Heat storage (HS) and electric boiler (EB) are favorable alternatives for reducing curtailed wind power in terms of releasing heat and power linkage [12]. Several studies focused on HS and EB have also been made to identify their facilitation of wind power integration. Reference [13] analyzed the possibilities of CHPs and HS balancing large scale of wind power and the optimal capacity of HS. In [14], research of optimal combination of PHS and EB in West Inner Mongolia was carried out, which claimed that PHS was less cost-effective than $\mathrm{EB}$ with the same reduction of surplus wind power. In [15], both environmental benefits and economic benefits were included in the objective function which was used to calculate the optimum capacity of EB when all of the curtailed wind power has to be accommodated. Reference [16] put forward several evaluation indexes to weigh the effects of HS and EB added to the cogeneration system on wind power accommodation. In [17-22], the performance of HS and EB on decoupling thermal-electrical production 
was further analyzed. All of the studies mentioned above have discussed the different approaches for better wind power integration, but few of them have compared the economic benefits of PHS as being the quintessential example of electrical storages with thermal devices.

This paper focuses on the economic evaluation of PHS, HS, and EB for the promotion of wind power integration. The economic analysis is conducted on the basis of calculating the capacities of these three facilities. Further, two linear models are established following the principle of "ordering power by heat $(\mathrm{OPH})$ " or "ordering heat by power $(\mathrm{OHP})$," respectively, to obtain the expected capacities. This paper is organized as follows. Section 2 is devoted to introducing the operation characteristics of $\mathrm{CHP}$ units and constructing $\mathrm{OPH}$ and $\mathrm{OHP}$ models while Section 3 presents the economic analysis of the three alternatives on the foundation of Section 2. Case studies and discussion are given in Section 4. Finally, conclusions are drawn in Section 5.

\section{Proposed OPH and OHP Models}

2.1. Operation Characteristic of CHP Unit. Two main types of CHP units, the back-pressure units and extraction-condensing units, are used worldwide in the power system. The heat output of a back-pressure unit is proportional to the power output while the heat and power outputs of an extractioncondensing unit are not certain to a proportional relationship. We just focused on the extraction-condensing units in this study since this type of CHP units is widely installed in Northern China. For simplicity, all the CHPs mentioned below are in terms of extraction-condensing units.

The feasible operation region of a CHP is characterized as an irregular quadrilateral or a polygon which is illustrated in Figure 1. The operation zone of a CHP is assumed to be convex so that the electric power $P_{i}^{t}$, thermal power $Q_{i}^{t}$, and operating $\operatorname{cost} C_{i}^{t}$ of a CHP can be represented as the linear convex combination of the extreme points. Several studies [23-25] related to the convexity of the CHP unit have been done, and the demonstrated results enable verifying the linear expression of the operating region as follows:

$$
\begin{aligned}
& Q_{i}^{t}=\sum_{k=1}^{M_{i}} q_{i, k} x_{i, k}^{t} \\
& P_{i}^{t}=\sum_{k=1}^{M_{i}} p_{i, k} x_{i, k}^{t} \\
& C_{i}^{t}=\sum_{k=1}^{M_{i}} c_{i, k} x_{i, k}^{t} \\
& \sum_{k=1}^{M_{i}} x_{i, k}^{t}=1,0 \leq x_{i, k}^{t} \leq 1,
\end{aligned}
$$

where $p_{i, k}, q_{i, k}$, and $c_{i, k}$ are the values of power, heat, and cost of the $k$ th extreme point; $M_{i}$ is the number of extreme points for the $i$ th CHP; $x_{i, k}^{t}$ is the combination coefficient. It is worth mentioning that numerous subsets of extreme points are eligible for representing a given operating status $\left(P_{i}^{t}, Q_{i}^{t}\right)$.

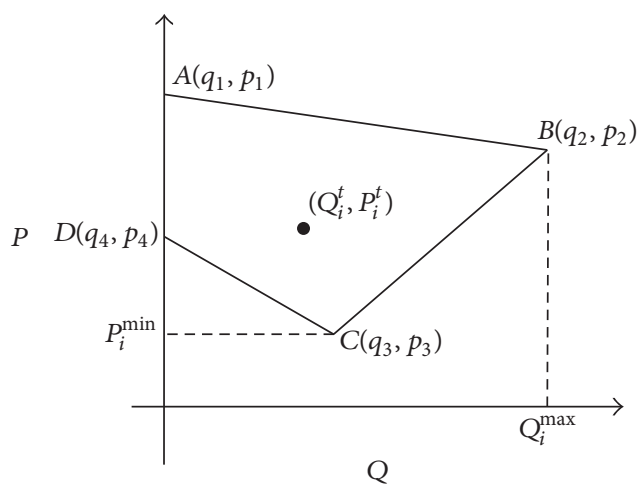

FIGURE 1: The feasible operating region of CHP.

2.2. Ordering Power by Heat (OPH) Model. The electric power produced by CHP units is determined by the thermal power which is the major barrier for the flexibility of CHP. This characteristic is the very foundation of the OPH model which is formulated with the objective function of minimizing the wasted wind power on the premise of meeting the daily heat demand.

Objective Function

$$
\min \sum_{t \in T}\left(P_{w}-P_{w x}^{t}\right)
$$

Electric Power Balance Constraint

$$
\sum_{i=1}^{I} \sum_{k=1}^{M_{i}} p_{i, k} x_{i, k}^{t}+\sum_{j=1}^{J} P_{j x}^{t}+P_{w x}^{t}=P_{e}^{t} ;
$$

Thermal Power Balance Constraint

$$
\sum_{i=1}^{I} \sum_{k=1}^{M_{i}} q_{i, k} x_{i, k}^{t}=P_{h}^{t}
$$

Generation Output Constraint

$$
\begin{aligned}
& 0 \leq P_{w x}^{t} \leq P_{w}^{t} \\
& \sum_{k=1}^{M_{i}} x_{i, k}^{t}=1, \quad 0 \leq x_{i, k}^{t} \leq 1 \\
& P_{j}^{\min } \leq P_{j x}^{t} \leq P_{j}^{\max } ;
\end{aligned}
$$

Ramp Rate Constraint

$$
\begin{aligned}
& -P_{i}^{\text {up }} \leq \sum_{k=1}^{M_{i}} p_{i, k} x_{i, k}^{t-1}-\sum_{k=1}^{M_{i}} p_{i, k} x_{i, k}^{t} \leq P_{i}^{\text {down }} \\
& -P_{j}^{\text {up }} \leq P_{j x}^{t-1}-P_{j x}^{t} \leq P_{j}^{\text {down }},
\end{aligned}
$$


where $I$ and $J$ are the numbers of CHP and power-only units, respectively; $T$ is the scheduling period; $P_{j x}^{t}$ is the power generated by the $j$ th unit at period $t ; P_{h}^{t}$ and $P_{e}^{t}$ are the power load and heat load; $P_{w}^{t}$ and $P_{w x}^{t}$ are the forecasted and integrated wind power; $P^{\text {up }}$ and $P^{\text {down }}$ are the rates of ramping up and down, respectively.

We can obtain the total amount of wasted wind power which would be accommodated directly by PHS and make the operating strategy of PHS by solving this linear $\mathrm{OPH}$ model.

2.3. Ordering Heat by Power (OHP) Model. Contrary to the $\mathrm{OPH}$ model, the OHP model is established following the principle of "ordering heat by power"; that is, the electric power is given priority to be regulated to accommodate the total wind power as far as possible and part of thermal demand which cannot be meet by CHPs would be supplied by heat compensators. A state vector, $V(t)$, is proposed to indicate the operating mode of heat compensator at period $t: V(t)=1$ means the requirement of heat compensation and $V(t)=0$, vice versa.

The minimum power output and the equivalent power load of the cogeneration system are noted as follows: $E_{\min }$ and $P_{\text {load }}^{t}$, respectively.

$$
\begin{aligned}
& E_{\text {min }}=\sum_{i=1}^{I} P_{i}^{\min }+\sum_{j=1}^{j} P_{j}^{\min } \\
& P_{\text {load }}^{t}=P_{e}^{t}-P_{w}^{t} .
\end{aligned}
$$

It is obvious that when $E_{\min }>P_{\text {load }}^{t}$ the wind power is bound to be curtailed and thus $V(t)=1$. When $E_{\min }<P_{\text {load }}^{t}$, the value of $V(t)$ has to be further defined by the difference between the maximum heat output of CHPs and heat load. The OHP model is formulated as follows:

\section{Objective Function}

$$
\max \sum_{i=1}^{I} \sum_{k=1}^{M_{i}} q_{i, k} x_{i, k}^{t}
$$

Electric Power Balance Constraint

$$
\sum_{i=1}^{I} \sum_{k=1}^{M_{i}} p_{i, k} x_{i, k}^{t}+\sum_{j=1}^{J} P_{j x}^{t}=P_{\mathrm{load}}^{t}
$$

Other constraints contain (4) and (6)-(9). The value of $V(t)$ is determined with the discriminant function:

$$
V(t)=\left\{\begin{aligned}
1, & \text { if } P_{h}^{t}>\sum_{i=1}^{I} Q_{i, t}^{\text {avail }} \\
0, & \text { if } P_{h}^{t}<\sum_{i=1}^{I} Q_{i, t}^{\text {avail }},
\end{aligned}\right.
$$

where $Q_{i, t}^{\text {avail }}$ is the maximum available thermal power of the $i$ th CHP unit solved by (11). $P_{h}^{t}<\sum_{i=1}^{I} Q_{i, t}^{\text {avail }}$ means that the heat power produced by CHP units is sufficient for heat supply while $P_{h}^{t}>\sum_{i=1}^{I} Q_{i, t}^{\text {avail }}$ means that the heat compensator is required for auxiliary heating.

\section{Economic Analysis}

The economic analysis is carried out based on the optimal results of OPH and OHP models with typical daily load and wind power curves. The net benefit is used as the index to measure the performance of different solutions in facilitating wind power integration.

3.1. Pumped Hydrostorage (PHS). PHS is expected to consume surplus wind power during off-peak periods by pumping water from the lower reservoir to the upper one. And during peak load periods, the potential energy is transformed into electrical energy again, reducing the power produced by $\mathrm{CHP}$ and power-only units. Aiming at integrating the whole generated wind power, the minimum installed capacity of PHS, $O_{\mathrm{PHS}}$, should be larger than the surplus wind power in consideration of energy efficiency.

$$
O_{\mathrm{PHS}}=\frac{\sum_{t \in T_{w}}\left(P_{w}^{t}-P_{w x}^{t}\right) \Delta t}{\eta_{\mathrm{PHS}}},
$$

where $T_{w}$ is the set of the periods when the wind power was wasted. In view of the gross cost of PHS, only the construction cost and maintenance cost are taken into consideration, as well as HS and EB. Thus the annual average cost of PHS can be expressed as follows:

$$
\begin{aligned}
& C_{\mathrm{PHS}}^{c}=O_{\mathrm{PHS}} u_{\mathrm{PHS}}^{c} \frac{r(1+r)^{y_{\mathrm{PHS}}}}{(1+r)^{y_{\mathrm{PHS}}}-1} \\
& C_{\mathrm{PHS}}^{m}=O_{\mathrm{PHS}} u_{\mathrm{PHS}}^{c} \alpha_{\mathrm{PHS}} \\
& C_{\mathrm{PHS}}^{\Sigma}=C_{\mathrm{PHS}}^{c}+C_{\mathrm{PHS}}^{m},
\end{aligned}
$$

where $\eta_{\mathrm{PHS}}$ is the energy efficiency; $C_{\mathrm{PHS}}^{c}$ is the converted annual construction cost; $C_{\mathrm{PHS}}^{m}$ and $C_{\mathrm{PHS}}^{\Sigma}$ are the maintenance cost and gross cost, respectively; $u_{\mathrm{PHS}}^{c}$ is the unit construction cost; $r$ is the bank lending rates; $y_{\mathrm{PHS}}$ is the lifetime of PHS; $\alpha_{\mathrm{PHS}}$ is the fixed annual maintenance cost ratio.

The economic benefits created by PHS during the daily scheduling period include two parts: the coal saved by replacing power generation of CHP and power-only units during peak load periods and the carbon emission cost reduced by coal saving. The evaluation model is given by

$$
B_{\mathrm{PHS}}=\left(u^{\text {coal }}+u^{\mathrm{car}} \varepsilon\right)\left(\sum_{t \in T_{w}}\left(P_{w}^{t}-P_{w x}^{t}\right) \Delta t\right) p_{\mathrm{av}}^{\text {coal }} .
$$
follows:

The daily net benefits of PHS should be expressed as

$$
R_{\mathrm{PHS}}=B_{\mathrm{PHS}}-\frac{C_{\mathrm{PHS}}^{\Sigma}}{D},
$$

where $u^{\text {coal }}$ is the cost of per ton of coal equivalent (Tce); $u^{\text {car }}$ is the cost of carbon emission; $\varepsilon$ is $\mathrm{CO}_{2}$ emission of per ton coal; 
$\Delta t$ is the duration of each segment; $p_{\mathrm{av}}^{\text {coal }}$ is the average coal consumption of electric power generation; $D$ is the number of heating days per year.

3.2. Heat Storage (HS). It is possible to introduce an HS using water as the energy storage media to reconcile the conflict between electric peak-shaving and heat supply [26]. The HS plays a role in thermal-load-shifting, similar to the load shifting of PHS. During the daytime, the CHPs are forced to produce extra thermal power for heat charging of HS. Then the stored thermal energy is released to ease the heat supply burden of CHPs during the nighttime. The capacity of HS is dependent on the requirement of heat compensation, which is calculated as follows:

$$
O_{\mathrm{HS}}=\frac{\sum_{t \in T}\left(P_{h}^{t}-\sum_{i \in I} Q_{i, t}^{\text {avail }}\right) \Delta t}{1-\eta_{\mathrm{HS}}^{\text {loss }}},
$$

where $\eta_{\mathrm{HS}}^{\text {loss }}$ is the heat accumulation loss of HS.

The annual average cost of HS is expressed as follows:

$$
\begin{aligned}
& C_{\mathrm{HS}}^{c}=O_{\mathrm{HS}} u_{\mathrm{HS}}^{c} \frac{r(1+r)^{y_{\mathrm{HS}}}}{(1+r)^{y_{\mathrm{HS}}}-1} \\
& C_{\mathrm{HS}}^{m}=O_{\mathrm{HS}} u_{\mathrm{HS}}^{c} \alpha_{\mathrm{HS}} \\
& C_{\mathrm{HS}}^{\Sigma}=C_{\mathrm{HS}}^{c}+C_{\mathrm{HS}}^{m} .
\end{aligned}
$$

In fact, the gross thermal power produced by CHPs during the scheduling period increases slightly because of the heat loss of HS. But the gross electric power supplied by CHPs reduces to integrate more wind power since the HS promotes the flexibility of CHPs. Thus both the increased thermal power and the reduced electric power generated by CHP have an effect on the economic calculation, including coal cost and carbon emission cost. The economic benefits and net benefits are calculated as follows:

$$
\begin{aligned}
B_{\mathrm{HS}} & =\left(u^{\text {coal }}+u^{\text {car }} \varepsilon\right) \\
\cdot & {\left[\left(\sum_{t \in T_{w}}\left(P_{w}^{t}-P_{w x}^{t}\right) \Delta t\right) p_{\mathrm{av}}^{\text {coal }}-O_{\mathrm{HS}} \eta_{\mathrm{HS}}^{\text {loss }} q_{\mathrm{av}}^{\text {coal }}\right] } \\
R_{\mathrm{HS}} & =B_{\mathrm{HS}}-\frac{C_{\mathrm{HS}}^{\Sigma}}{D},
\end{aligned}
$$

where $q_{\mathrm{av}}^{\text {coal }}$ is the average coal consumption of CHPs for thermal power generation.

3.3. Electric Boiler (EB). An EB is usually installed near the CHP plant and activated during the periods, $T_{w}$. Not only can it consume wind power directly as PHS, but also it can supply thermal power as HS. To explain the impact of this specific characteristic on the operation of CHP, Figure 2 is shown for detailed illustration.

$Q_{i}^{\text {need }}$ represents the essential thermal power obtained by the OPH model where the thermal demand is met primarily. $P_{i}^{\text {need }}$ represents the demanded electric power output

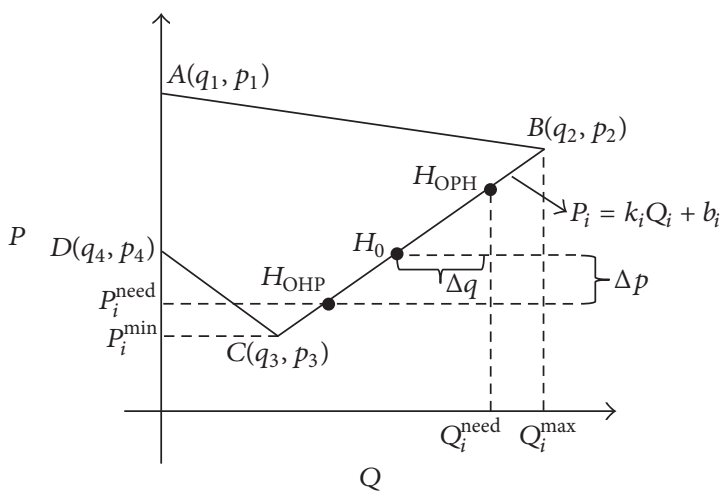

FIgURE 2: Operating region of $\mathrm{CHP}$ with electric boiler.

obtained by the OHP model where the wind power integration is preferred. Neither operating point $H_{\mathrm{OHP}}$ nor $H_{\mathrm{OPH}}$ of CHPs is available for the system to meet thermal demand without wasting wind power. Nevertheless, the CHP unit could be adjusted to the operating point, $H_{0}$, to satisfy the regulating requirement of thermal and electric power hopefully with assistance of EB.

After the EB being integrated into the system, the produced thermal power of the $i$ th CHP unit is reduced by $\Delta q_{i, t}$ and the electric power is increased by $\Delta p_{i, t}$. The coupling relationship of thermal and electric power during each $\Delta t$ could be expressed as follows:

$$
\begin{aligned}
p_{i, t}^{\text {need }}+\Delta p_{i, t} & =k_{i}\left(Q_{i, t}^{\text {need }}-\Delta q_{i, t}\right)+b_{i} \\
\Delta q_{i, t} & =\Delta p_{i, t} \eta_{\mathrm{EB}},
\end{aligned}
$$

where $\eta_{\mathrm{EB}}$ is the energy efficiency of EB; $k_{i}$ and $b_{i}$ are the parameters of the line segment $C B$ in Figure 2. As the gross increased electric power of CHPs is caused by the power consumption of $\mathrm{EB}$, the minimum capacity of $\mathrm{EB}$ is given by

$$
O_{\mathrm{EB}}=\max _{t \in T_{w}} \sum_{i \in I} \Delta p_{i, t} .
$$

The annual average cost of EB is given by

$$
\begin{aligned}
& C_{\mathrm{EB}}^{c}=O_{\mathrm{EB}} u_{\mathrm{EB}}^{c} \frac{r(1+r)^{y_{\mathrm{EB}}}}{(1+r)^{y_{\mathrm{EB}}}-1} \\
& C_{\mathrm{EB}}^{m}=O_{\mathrm{EB}} u_{\mathrm{EB}}^{c} \alpha_{\mathrm{EB}} \\
& C_{\mathrm{EB}}^{\Sigma}=C_{\mathrm{EB}}^{c}+C_{\mathrm{EB}}^{m} .
\end{aligned}
$$

With the EB meeting part of the thermal demand and consuming more wind power, coal and carbon emission cost of the cogeneration system reduced even more. The economic benefits and net benefits are given by

$$
\begin{aligned}
B_{\mathrm{EB}} & =\left(u^{\text {coal }}+u^{\mathrm{car}} \varepsilon\right) \\
\cdot & \sum_{t \in T_{w}}\left[\left(P_{w}^{t}-P_{w x}^{t}\right) p_{\mathrm{av}}^{\mathrm{coal}}+\Delta q_{i, t} q_{\mathrm{av}}^{\mathrm{coal}}\right] \Delta t \\
R_{\mathrm{EB}} & =B_{\mathrm{EB}}-\frac{C_{\mathrm{EB}}^{\Sigma}}{D} .
\end{aligned}
$$




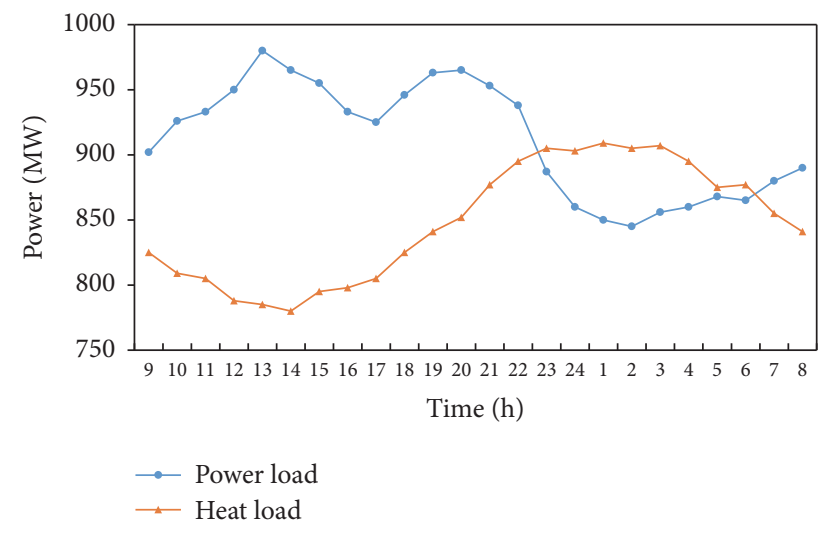

Figure 3: Curves of power load and heat load.

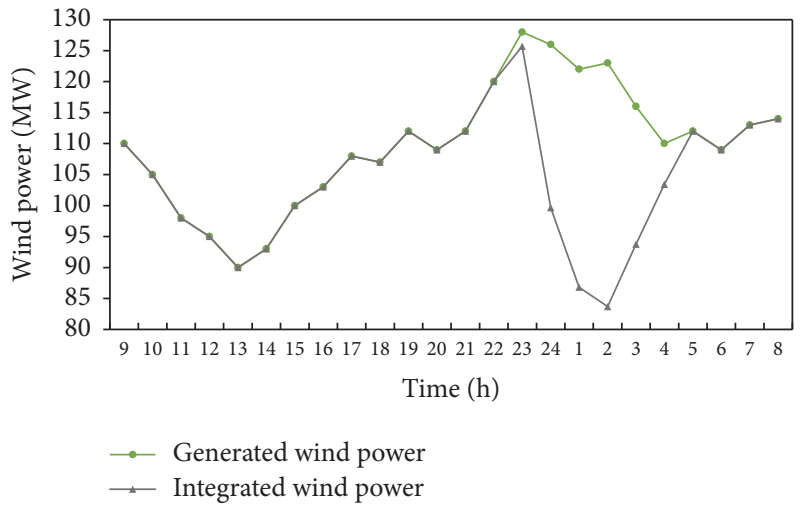

FIGURE 4: Comparison of generated and integrated wind power.

Except for the calculation of $R_{*}$, reflecting directly the net benefits, performance of these three different facilities for wind power integration is further discussed with numerable examples in Section 4.

\section{Case Studies}

4.1. Case 1. In this study, the cogeneration system structure is downscaled based on the actual proportions of installed power energy sources in Northern China. Three CHP units are noted as CHP1, CHP2, and CHP3; two power-only units are noted as CON1 and CON2. The power source structure is listed in Table 1. Detailed information of the units is shown in Table 2. The scheduling period, $T$, is 24 hours and $\Delta t$ is 1 hour. $D$ is 180 days. Figure 3 shows the curves of typical daily thermal power load and electric power load. Parameters related to economic analysis are given in Table 3.

By solving the OPH and OHP models, the authors get the same result of $T_{w}$ which is from 23:00 pm to the next day 4:00 am. Heat compensation is required during these periods if the thermal demand and power demand are simultaneously satisfied without wasting wind power. The curtailed wind power and necessary heat compensation of each period are listed in Table 4. Comparison of generated wind power with integrated wind power is shown in Figure 4. Figure 5 presents the curves of $Q_{i}^{\text {need }}$ and $P_{i}^{\text {need }}$. The installed capacity of PHS
TABLE 1: Power source structure.

\begin{tabular}{lcc}
\hline Power Source & Installed Capacity/MW & Proportion \\
\hline CHP & 800 & $67.8 \%$ \\
Power-only & 250 & $21.2 \%$ \\
Wind & 130 & $11.0 \%$ \\
\hline
\end{tabular}

TABLE 2: Parameters of CHP and power-only units.

\begin{tabular}{lccc}
\hline \multicolumn{4}{c}{ CHP Units } \\
Corner Points & CHP1 & CHP2 & CHP3 \\
\hline$\left(q_{1}, p_{1}\right) / \mathrm{MW}$ & $(0,323)$ & $(0,310)$ & $(0,210)$ \\
$\left(q_{2}, p_{2}\right) / \mathrm{MW}$ & $(357,241)$ & $(320,246)$ & $(240,155)$ \\
$\left(q_{3}, p_{3}\right) / \mathrm{MW}$ & $(154,150)$ & $(100,150)$ & $(124,100)$ \\
$\left(q_{4}, p_{4}\right) / \mathrm{MW}$ & $(0,150)$ & $(0,170)$ & $(0,100)$ \\
\hline \multicolumn{4}{c}{ Power-only Units } \\
Output Limits & \multicolumn{5}{c}{ CON1 } \\
\hline Maximum/MW & 150 & CON2 \\
Minimum/MW & \multicolumn{5}{c}{100} \\
\hline
\end{tabular}

TABle 3: Parameters related to economic analysis.

\begin{tabular}{lc}
\hline$\eta_{\mathrm{PHS}}$ & $80 \%$ \\
$\eta_{\mathrm{HS}}^{\text {loss }}$ & $4 \%$ \\
$\eta_{\mathrm{EB}}$ & $98 \%$ \\
$\alpha_{\mathrm{PHS}}$ & $1 \%$ \\
$\alpha_{\mathrm{HS}}$ & $0.5 \%$ \\
$\alpha_{\mathrm{EB}}$ & $0.5 \%$ \\
$u_{\mathrm{PHS}}^{\mathrm{c}}$ & $53.1 \mathrm{k} \$ / \mathrm{MWh}$ \\
$u_{\mathrm{HS}}^{c}$ & $5.3 \mathrm{k} \$ / \mathrm{MWh}$ \\
$u_{\mathrm{EB}}^{c}$ & $217 \mathrm{k} \$ / \mathrm{MW}$ \\
$p_{\mathrm{av}}^{\text {coal }}$ & $330 \mathrm{~kg} / \mathrm{MWh}$ \\
$q_{\mathrm{av}}^{\text {coal }}$ & $154 \mathrm{~kg} / \mathrm{MWh}$ \\
$r$ & $6 \%$ \\
$y_{\mathrm{PHS}}$ & $50 \mathrm{a}$ \\
$y_{\mathrm{HS}}$ & $20 \mathrm{a}$ \\
$y_{\mathrm{EB}}$ & $20 \mathrm{a}$ \\
$u^{\text {coal }}$ & $120 \$ / \mathrm{ton}$ \\
$u^{\text {car }}$ & $4 \$ / \mathrm{ton}$ \\
$\varepsilon$ & 2.6 \\
\hline
\end{tabular}

should be $132.02 / 0.8=165.03 \mathrm{MWh}$ as the aggregated curtailed wind power is $132.02 \mathrm{WMh}$. The capacity of HS is $278.44 /(1-0.04)=290.04 \mathrm{MWh}$. The capacity of EB is at least 26.84 MW by solving (21)-(22). Investment costs and economic benefits displayed with histograms in Figure 6 are easy to be calculated since the capacities of these facilities have been known. It can be seen that installing HS needs the least investment cost but gets the maximum net benefit by $4660.85 \$$ in the case of integrating the same amount of surplus wind power. The EB solution is only second to HS with the net benefit of $4472.21 \$$ and it creates the most economic benefit by saving coal consumed by electric and thermal power generation concurrently. 


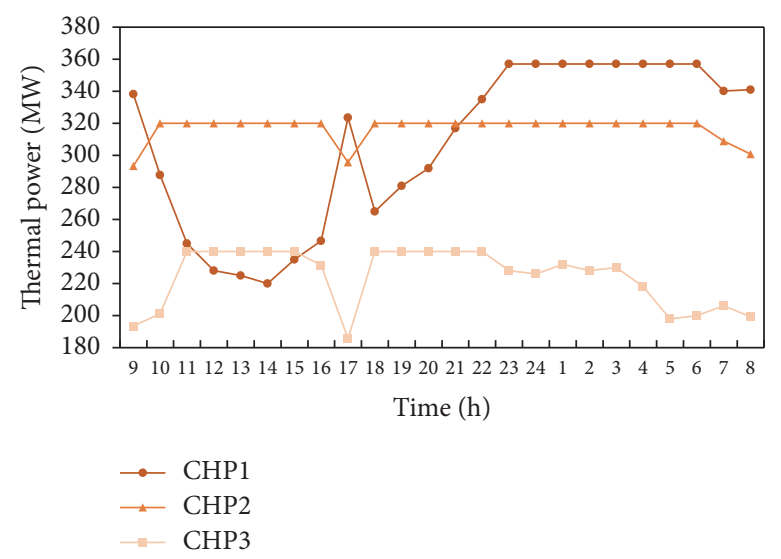

(a) Essential thermal power $Q_{i}^{\text {need }}$

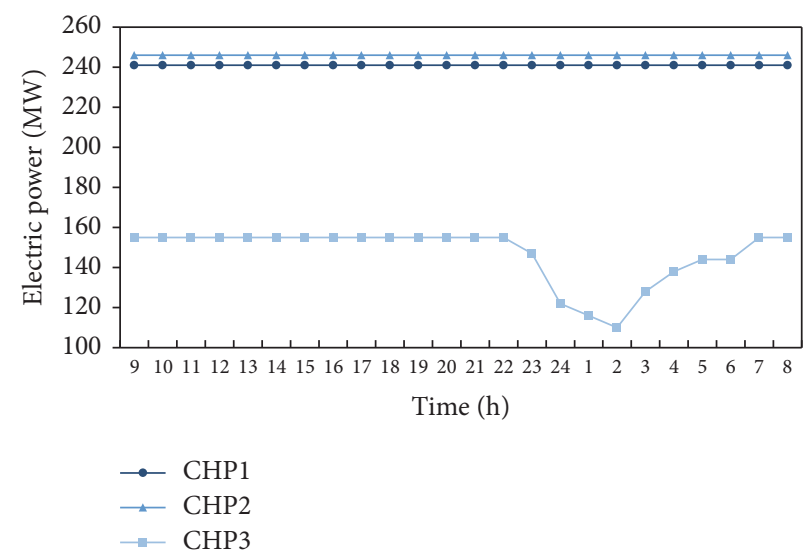

(b) Essential electric power $P_{i}^{\text {need }}$

FIgURE 5: Curves of essential thermal and electric power.

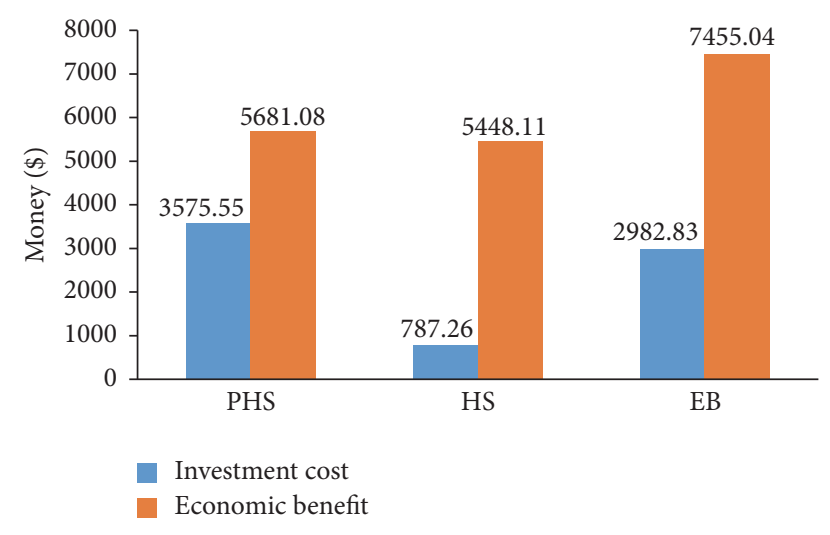

FIGURE 6: Investment costs and economic benefits of PHS, HS and EB.

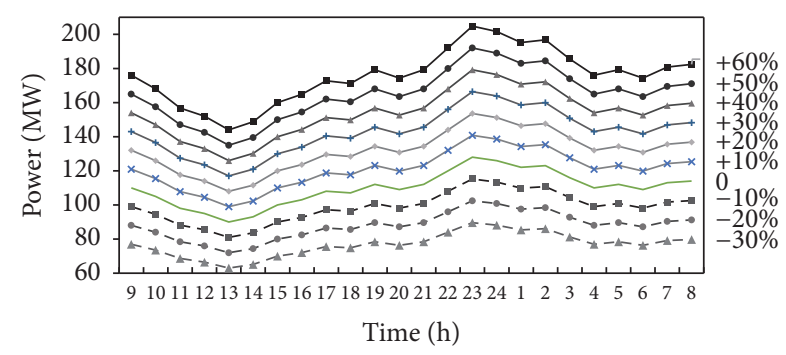

Figure 7: Percentage changes of wind power.

4.2. Case 2. The net benefits of different solutions are closely associated with the amount of generated wind power and curtailed wind power. Taking the results in Case 1 as the reference, Figures 7 and 8 show the changes of capacities along with the changes of wind power by moving the curve of generated wind power up and down with the step size of $10 \%$.

As shown in Figure 8, the required capacity of PHS is consistent with the variation of wind power. But the capacity of HS tends to decrease when the wind power is increased by

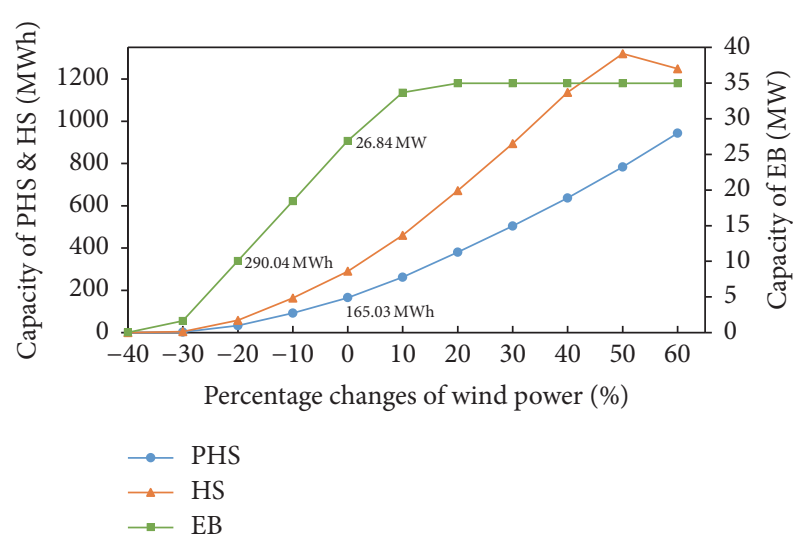

Figure 8: Capacity changes of PHS, HS, and EB.

TABLE 4: Curtailed wind power and compensated heat power.

\begin{tabular}{lcc}
\hline Periods & Curtailed Wind/MW & Compensated Heat/MWh \\
\hline 23:00 & 2.31 & 4.87 \\
24:00 & 26.36 & 55.60 \\
1:00 & 35.21 & 74.25 \\
$2: 00$ & 39.31 & 82.91 \\
$3: 00$ & 22.26 & 46.95 \\
$4: 00$ & 6.57 & 13.85 \\
\hline Total & 132.02 & 278.44 \\
\hline
\end{tabular}

more than $50 \%$, which is because the available extra thermal power produced by CHPs for heat accumulation starts to decrease with such high wind power generation during the peak load periods. Moreover, the capacity of EB remains unchanged when the wind power increases by more than $20 \%$, verifying the excellent flexibility of EB in adjusting power output with the amount of surplus wind power.

As can be seen from Figure 9, the net benefits of installing PHS, HS or EB for accommodating surplus wind power show a significant growth trend. Thus it is definitely profitable to reduce surplus wind power by integrating PHS, HS, or EB into 


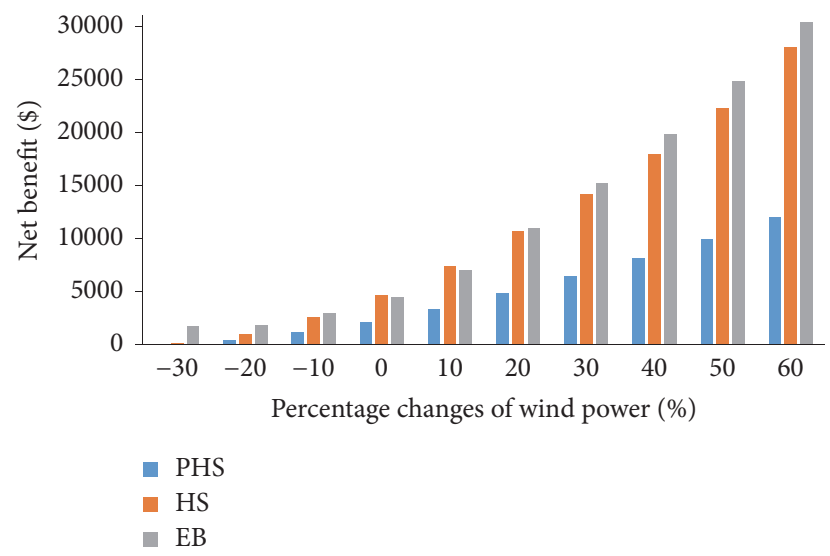

FIGURE 9: Net benefit changes of PHS, HS, and EB.

the cogeneration system. In addition, solutions of utilizing HS and EB for heat compensation have distinct advantages of economic benefits in comparison with PHS. And the net benefit created by installing EB comes to be the best when the generated wind power reaches a high level.

\section{Conclusion}

This paper presents an evaluation of the economic value of pumped hydrostorage (PHS), heat storage (HS), and electric boiler (EB) in facilitating wind power integration in the cogeneration power system. This evaluation is accomplished by analyzing the investment costs and economic benefits introduced by installing PHS, HS, or EB. Two models denoted as "ordering power by heat (OPH)" model and "ordering heat by power (OHP)" model for obtaining the essential electric power and thermal power required by satisfying the load demand without wind power curtailment are proposed in this study. The minimum capacities of PHS, HS, and EB needed for integrating the same amount of wind power and the subsequent economic analysis are performed on the foundation of the results of these two models.

The cases demonstrated the feasibility of accommodating wasted wind power by these auxiliaries. The capacity of PHS which plays the role of electrical storage is determined by the aggregated surplus wind power and it costs much more than HS and EB. It is economical to utilize the HS to alleviate the conflict between wind power and thermal demand. But the capacity of HS is limited by the heating ability of CHPs since the accumulated thermal power is supplied by CHPs. Instead, the EB shows better performance for promotion of wind power integration with superior economic advantage when the proportion of wind power is very high in the system. Therefore, the HS is preferred if the curtailed wind power is not too much while the EB should be given priority if the wind power develops to an even higher level in the future.

Although the data is simplified in the cases, the conclusion would not be affected by the accuracy of the calculation. More details involved in the practical projects will be considered in the future research.

\section{Conflicts of Interest}

The authors declare that there are no conflicts of interest regarding the publication of this paper.

\section{References}

[1] I. Paraschivoiu, O. Trifu, and F. Saeed, "H-Darrieus wind turbine with blade pitch control," International Journal of Rotating Machinery, vol. 2009, Article ID 505343, 7 pages, 2009.

[2] R. X. Yuan, J. Ye, J. Z. Lei, and T. M. Li, "Integrated combined heat and power system dispatch considering electrical and thermal energy storage," Energies, vol. 9, no. 6, pp. 1-17, 2016.

[3] Z. G. Li, W. C. Wu, M. Shahidehpour et al., "Combined heat and power dispatch considering pipeline energy storage of district heating network," IEEE Transactions on Sustainable Energy, vol. 7, no. 1, pp. 12-22, 2016.

[4] B. Dunn, H. Kamath, and J. M. Tarascon, "Electrical energy storage for the grid: a battery of choices," Science, vol. 334, pp. 928-935, 2011.

[5] J.-N. Liu, Z.-Y. Ren, S.-W. Wu, and Y.-L. Tang, “Theoretical vibration analysis on $600 \mathrm{Wh}$ energy storage flywheel rotor-active magnetic bearing system," International Journal of Rotating Machinery, vol. 2013, Article ID 512674, 11 pages, 2013.

[6] K. Jiang, H. M. Li, W. Li, and S. J. Cheng, "On several battery technologies for power grids," Automation of Electric Power System, vol. 37, no. 1, pp. 47-53, 2013.

[7] H. R. Zhao, Q. W. Wu, S. J. Hu, H. H. Xu, and C. N. Rasmussen, "Review of energy storage system for wind power integration support," Applied Energy, vol. 137, pp. 545-553, 2015.

[8] N. Zhang, C. Kang, D. Kirschen et al., "Planning pumped storage capacity for wind power integration," IEEE Transactions on Sustainable Energy, vol. 4, no. 2, pp. 393-401, 2013.

[9] A. Tuohy and M. O'Malley, "Pumped storage in systems with very high wind penetration," Energy Policy, vol. 39, no. 4, pp. 1965-1974, 2011.

[10] J. I. Perez-Diaz and J. Jimenez, "Contribution of a pumpedstorage hydropower plant to reduce the scheduling costs of an isolated power system with high wind power penetration," Energy, vol. 109, pp. 92-104, 2016.

[11] B. Xiao, J. Cong, X. F. Gao, and Y. Gu, "A method to evaluate comprehensive benefits of hybrid wind power-pumped storage system," Power System Technology, vol. 38, no. 3, pp. 338-342, 2014.

[12] X. Y. Chen, C. Q. Kang, M. O. Malley et al., "Increasing the flexibility of combined heat and power for wind power integration in China: modeling and implications," IEEE Transactions on Power Systems, vol. 30, no. 4, pp. 1848-1857, 2015.

[13] S. Rinne and S. Syri, "The possibilities of combined heat and power production balancing large amounts of wind power in Finland," Energy, vol. 82, pp. 1034-1046, 2015.

[14] N. Zhang, X. Lu, M. B. McElroy et al., "Reducing curtailment of wind electricity in China by employing electric boilers for heat and pumped hydro for energy storage," Applied Energy, vol. 184, pp. 987-994, 2016.

[15] D. Liu, G. W. Zhang, B. H. Huang, and W. W. Liu, "Optimum electric boiler capacity configuration in a regional power grid for a wind power accommodation scenario," Energies, vol. 9, no. 3, pp. 1-13, 2016.

[16] S. Rong, Z. M. Li, and W. X. Li, "Investigation of the promotion of wind power consumption using the thermal-electric decoupling techniques," Energies, vol. 8, no. 8, pp. 8613-8629, 2015. 
[17] A. Christidis, C. Koch, L. Pottel, and G. Tsatsaronis, “The contribution of heat storage to the profitable operation of combined heat and power plants in liberalized electricity markets," Energy, vol. 41, pp. 75-82, 2012.

[18] H. Dries, P. Leen, H. Lieve, and D. William, “The impact of thermal storage on the operational behaviour of residential CHP facilities and the overall $\mathrm{CO}_{2}$ emissions," Renewable and Sustainable Energy Reviews, vol. 11, no. 6, pp. 1227-1243, 2007.

[19] Y. L. Yang, K. Wu, X. Yan, J. C. Gao, and H. Long, “The largescale wind power integration using the integrated heating load and heating storage control," in Proceedings of the IEEE Eindhoven PowerTech Conference, Eindhoven, The Netherlands, June 2015.

[20] T. Nuytten, B. Claessens, K. Paredis, J. V. Bael, and D. Six, "Flexibility of a combined heat and power system with thermal energy storage for district heating," Applied Energy, vol. 104, pp. 583591, 2013.

[21] Y. Cui, Z. Chen, G. G. Yan, and Y. H. Tang, "Coordinated wind power accommodating dispatch model based on electric boiler and CHP with thermal energy storage," Proceeding of the CSEE, vol. 36, no. 15, pp. 4072-4080, 2016.

[22] H. K. Chen, Y. J. Yu, and X. Jiang, "Optimal scheduling of combined heat and power units with heat storage for the improvement of wind power integration," in Proceedings of the IEEE PES Asia-Pacific Power and Energy Engineering Conference, Xian, China, October 2016.

[23] A. Rong and R. Lahdelma, "Efficient algorithms for combined heat and power production planning under the deregulated electricity market," European Journal of Operational Research, vol. 176, no. 2, pp. 1219-1245, 2007.

[24] F. Salgago and P. Pedrero, "Short-term operation planning on cogeneration systems: a survey," Electric Power Systems Research, vol. 78, no. 5, pp. 835-848, 2008.

[25] S. Makkonen and R. Lahdelma, "Non-convex power plant modelling in energy optimisation," European Journal of Operational Research, vol. 171, pp. 1113-1126, 2006.

[26] L. Chen, F. Xu, X. Wang, Y. Min, M. Ding, and P. Huang, "Implementation and effect of thermal storage in improving wind power accommodation," Proceedings of the CSEE, vol. 35, no. 17, pp. 4283-4290, 2015. 


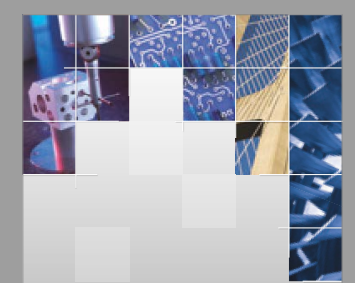

\section{Enfincering}
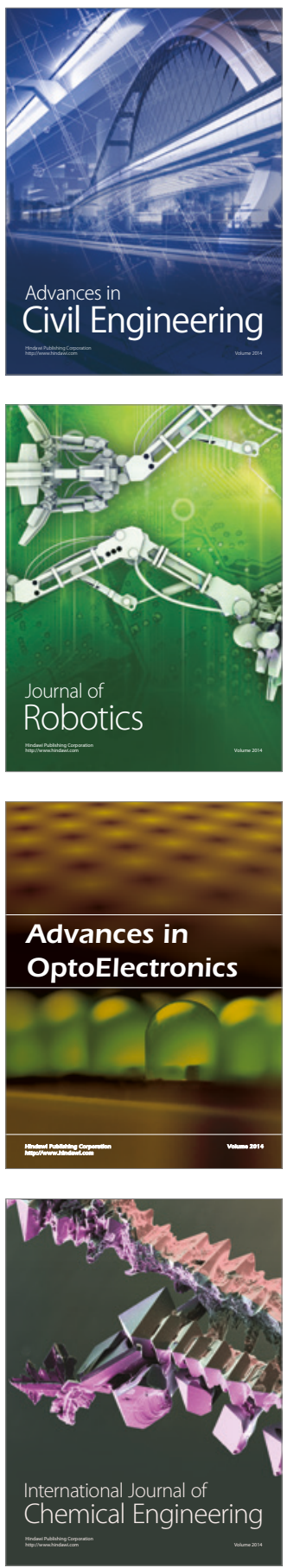

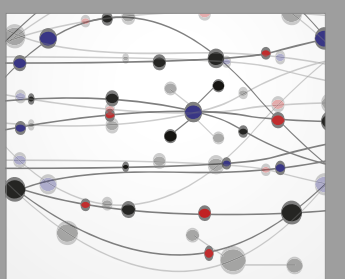

The Scientific World Journal

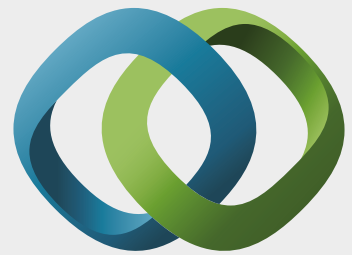

\section{Hindawi}

Submit your manuscripts at

https://www.hindawi.com
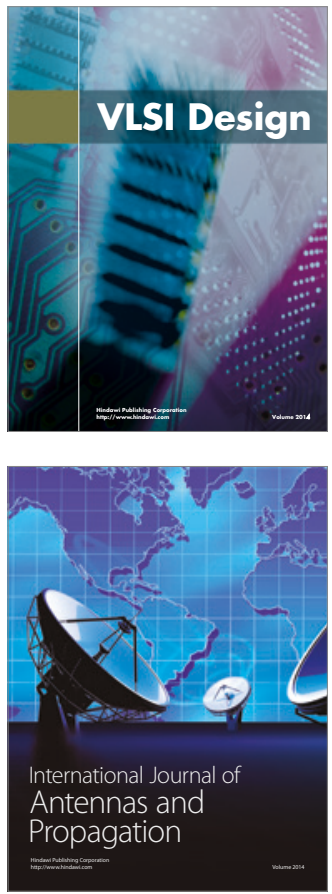

\section{Rotating}

Machinery
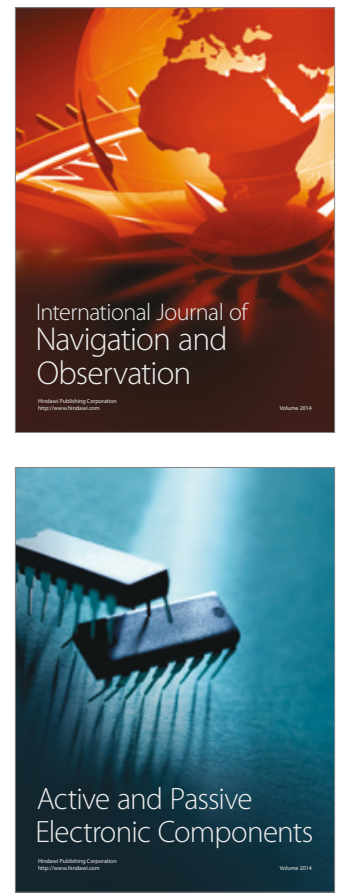
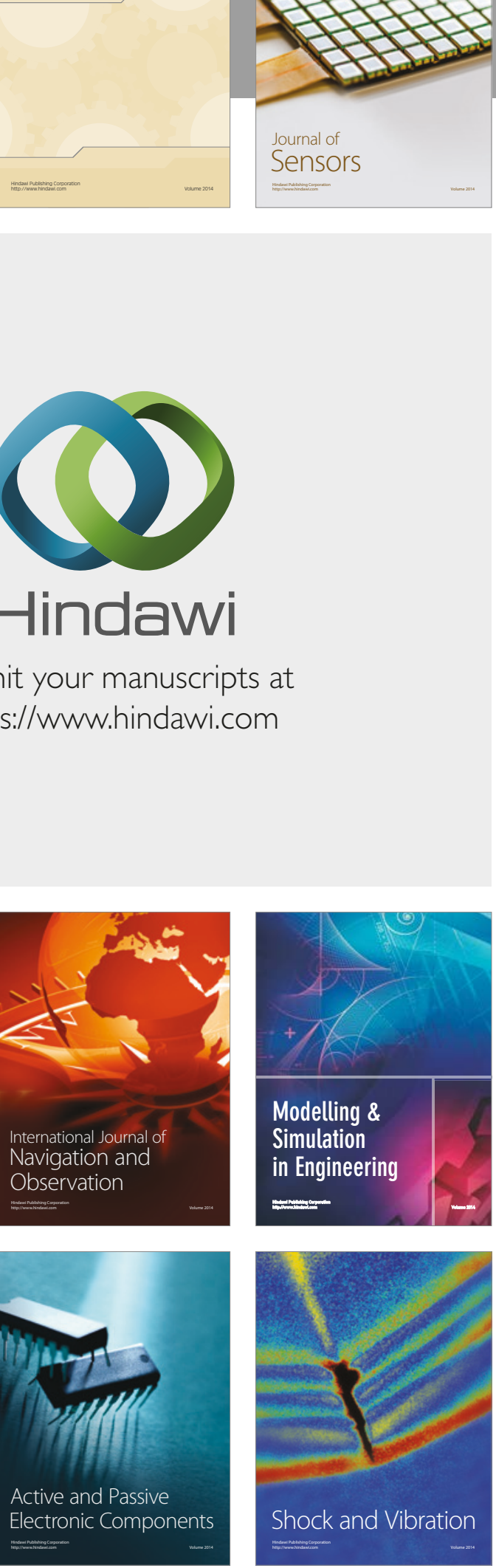
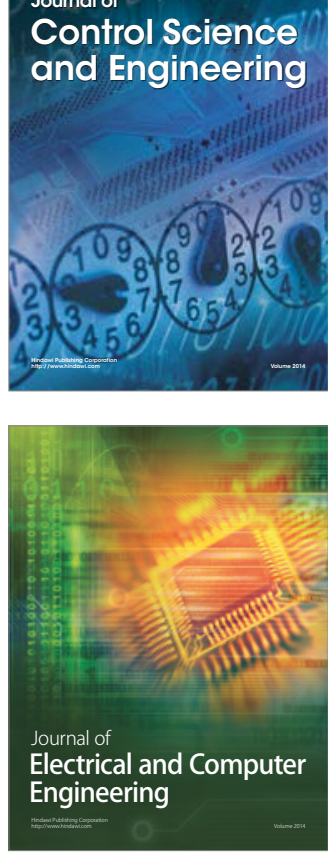

Distributed

Journal of

Control Science

and Engineering
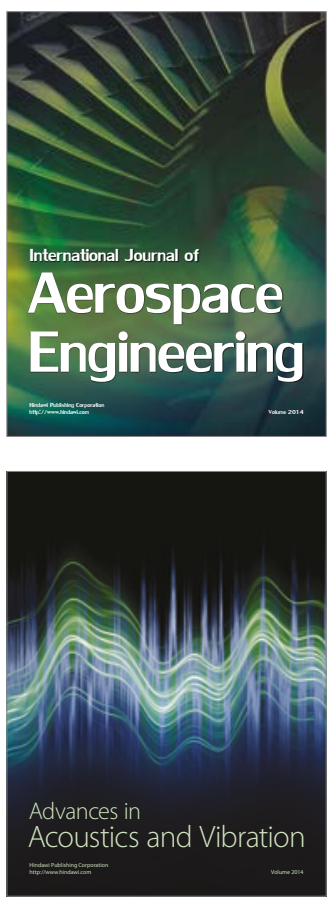

Sensor Networks 